\title{
The effect of resistance grooves on the fracture toughness of zirconia-based crowns from mono and cyclic loading
}

\author{
Tarek Q. Qasim ${ }^{1}$, Billal M. El-Masoud ${ }^{2}$, Ahmed M. Abu Laban ${ }^{2}$
}

Correspondence: Dr. Tarek 0. Oasim

'Department of Industrial Engineering, Faculty of Engineering, Jordan University of Science and Technology, Irbid, Jordan,

Email: tqqasim@just.edu.jo

2Department of Prosthodontics, Jordan University of Science and Technology, Irbid, Jordan

\section{ABSTRACT}

Objective: Prosthetic molar crowns in service are subjected to chewing loads, which cause a shift or dislodgment. The objective of this study is to investigate whether the addition of resistance grooves to the proximal surfaces of the abutment teeth would enhance the fracture resistance of the zirconia crowns and to compare between the patterns of cracks development on the zirconia crowns after the application of mono loading versus cyclic loading forces. Materials and Methods: Thirty-six all-ceramic zirconia cored crowns were prepared on the same abutment. Resistance grooves were added to the mesial and distal surfaces of 16 abutments. Before testing, all specimens subjected to thermal aging. Two groups of crowns were then subjected to cyclic axial and lateral forces for 1,250,000 cycles in aqueous conditions. Two groups of samples were also tested in monoloading fashion. Results: The crack pattern between mono and cyclic loading were compared. The crown fracture resistance was compared in the two types of abutments, with and without grooves. The results confirmed that the grooves addition had no effect on critical conditions to initiate failure in the case of mono loading. In cyclic loading, grooves addition increased the critical loads in the order of two. Failure patterns and location were obtained. Conclusions: The results showed that the location of retention grooves halted the failure in the surfaces where it was located in all loading mechanisms used in this study.

Key words: All ceramic crowns, chewing simulator, failure modes, thermal aging

\section{INTRODUCTION}

In dental prostheses, all ceramic crowns are replacing porcelain fused to metal crowns as a material of choice, zirconia as a tough inner layer and porcelain as top layer where biocompatibility and esthetics are critical issues. ${ }^{[1-3]}$ Several researches used hard spherical indenters "point contact" to study the failure of all-ceramic crown systems. Point contact magnifies the contact pressure, which represents extreme service conditions. The crack patterns and

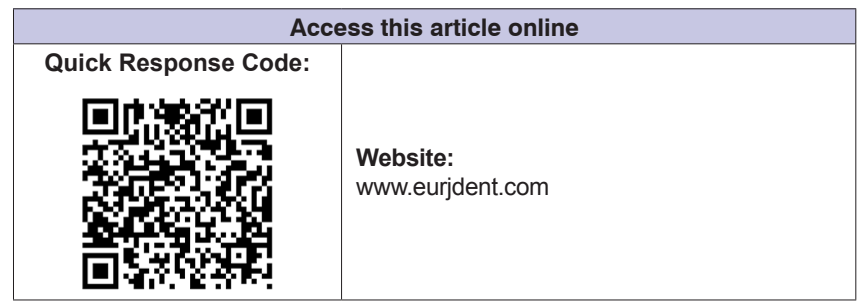

locations observed and reported using hard spherical indenters were limited to the occlusal top surface of the crown due to the concentration of tensile stresses around the small contact area. The top surface cracks fail to explain the failure modes observed in service of dental crowns at the distal, lingual, mesial, and buccal surfaces of the crown such as "semi-lunar" fracture pattern. ${ }^{[4]}$ Cracks locations and failure modes are also

This is an open access journal, and articles are distributed under the terms of the Creative Commons Attribution-NonCommercial-ShareAlike 4.0 License, which allows others to remix, tweak, and build upon the work non-commercially, as long as appropriate credit is given and the new creations are licensed under the identical terms.

For reprints contact: reprints@medknow.com

How to cite this article: Qasim TQ, El-Masoud BM, Abu Laban AM. The effect of resistance grooves on the fracture toughness of zirconiabased crowns from mono and cyclic loading. Eur J Dent 2018;12:491-5. DOI: 10.4103/ejd.ejd_207_18 
affected by the method of applied loads in testing; mono-loading and cyclic loading shows distinctive differences in cracks location and more interestingly in crack propagation to failure. The case of cyclic loading cracks was initiated at the side surfaces of the crowns and propagated rapidly upward as number of cycles increased near the occlusal surface. ${ }^{[5]}$ The argument of using point contact from hard spherical indenters to represent in service extreme conditions is valid, yet testing in cyclic dual loading (axial and lateral) brings the findings closer to the actual crown in service.

To avoid the high incidence of failure of dental restorations, several ceramic brands and processing systems found their way to the dental industry. ${ }^{[6-8]}$ Another proposed technique to resist crown failure in service is the addition of grooves on the proximal surfaces of the abutment tooth after preparation to receive a prosthetic crown. It has been suggested that when the force rotational arc moves away from one wall of the groove, it hits the other wall, so resistance is substantiated one way or the other. ${ }^{[9,10]}$ It is recommended that grooves should be routinely used in molars and to be placed in proximal areas. ${ }^{[11,12]}$

The aims of this study were to investigate whether the addition of resistance grooves to the proximal surfaces of the abutment teeth would enhance fracture resistance of the zirconia crowns. In addition, it was aimed to compare between the patterns of cracks development on zirconia crowns after application of mono loading versus cyclic loading forces.

\section{MATERIALS AND METHODS}

\section{Crown fabrication and materials used}

The abutment tooth considered in this study was prepared with nonoptimal parameters where retentive measures as groove boxes and pins needed in such cases. The primary preparation was made on a plastic lower first molar having an axial reduction of $1.5 \mathrm{~mm}$ on all cusps. In addition, facial and lingual reductions of $1 \mathrm{~mm}$ were made. The final tooth measures were buccolingual/mesiodistal ratio of 7.5/8.5 and occluso cervical/buccolingual ratio of $4 / 7.5$. Two grooves were added to the proximal surfaces of the abutment tooth; one on the mesial surface and one on the distal [Figure 1].

The grooves measured $1 \mathrm{~mm}$ in depth and $1 \mathrm{~mm}$ in width, extending $0.5 \mathrm{~mm}$ above the finish line to the height of the tooth placed mesially and distally

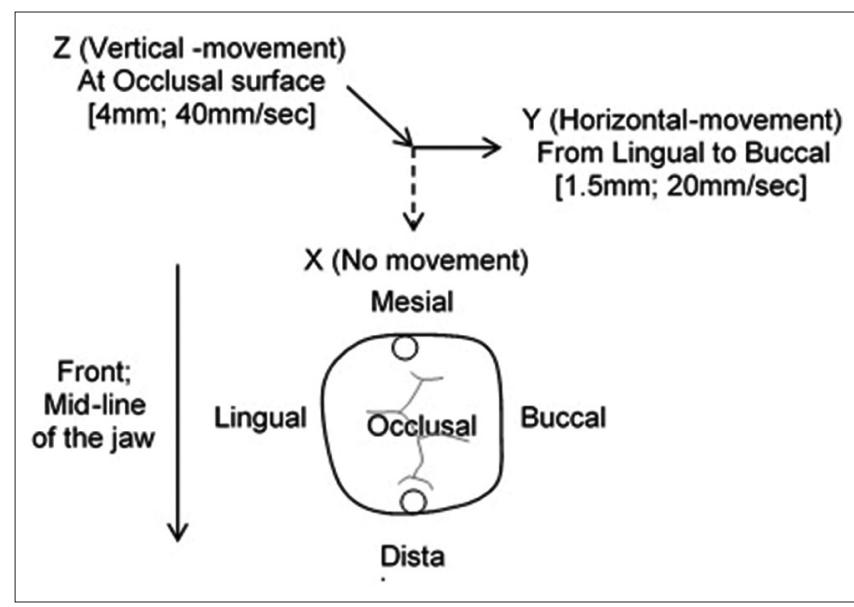

Figure 1: Schematic diagram showing top view of dental crown (the circles indicate the grooves locations) and the indenter movements (speed and distance) relative to the crown occlusal surface

[Figure 2]. The direction of the chewing was placed buccolingually, to mimic the chewing forces applied by the human jaws. Both stone dies were scanned using computer-aided design/computer-aided manufacturing CAD/CAM machine (NEO CAD 7.7). The Zirconia copings have overall thickness of $0.5 \mathrm{~mm}$ with the exception of the groove area. The CAD/ CAM method is widely used in dental prostheses. ${ }^{[13]}$ Two groups of eight zirconia copings where made for each abutment, zirconia compatible porcelain (Noritake-Japan) then veneered to all samples with $1 \mathrm{~mm}$ porcelain thickness. To hold the fabricated crowns in testing chamber, abutments for the crowns made from hybrid composite (Prime dent - USA). The composite built inside the crown and extended $8 \mathrm{~mm}$ below the crown edge, i.e., gum line. All specimens were subjected to thermal aging using a thermal cyclic machine for 6000 cycles $\left(5^{\circ} \mathrm{C}-55^{\circ} \mathrm{C}\right)$; the duration of each cycle was $60 \mathrm{~s}$ to simulate 5 years in oral service. Before testing, the samples fixed in the specimens holder using dental acrylic (Metropair- England) and left to cure slowly for $24 \mathrm{~h}$ at room temperature. According to manufacturer specifications, materials properties used in this study are summarized in Table 1.

\section{Testing}

The specimens were divided into four groups, two groups (with and without grooves) of $n=8$ each, tested in cyclic loading. The limitation of a number of samples tested in cyclic loading was the testing chambers number in the chewing simulator; it is recommended to fill all testing chambers with specimens during testing; in similar fashion, Kern et al. used eight specimens in his study to fill all chambers with specimens. ${ }^{[14]}$ Another two groups (with 


\begin{tabular}{llc}
\multicolumn{2}{l}{ Table 1: Materials properties used in this study } \\
\hline & Material & $\begin{array}{c}\text { Young's modulus, } \\
\text { E (GPa)* }\end{array}$ \\
\hline Indenter & Ni-Cr alloy steel & 270 \\
Crown top layer & Porcelain & 70 \\
Crown underlayer & Partially & 205 \\
Crown support (substrate) & Dentalized zirconia & \\
Resin cement & Resin cement & 15 \\
Acrylic & Denture acrylic & 15 \\
\hline${ }^{*}$ Manufacturer specifications & & 3.5 \\
\hline
\end{tabular}

and without grooves) of $n=10$ each tested under compressive mono-loading using universal testing. To mimic the action of human chewing conditions, all tests were done in wet conditions using distilled water in the test chamber at room temperature. The same stainless steel flat cylindrical indenter was used [Figure 3]. ${ }^{[15]}$ The indenter dimension area was large enough to cover the lateral movement of the samples during the cyclic testing.

Four testing chambers chewing simulator (CS 4.4 SD Mechatronik, Germany) utilized in this study. The simulator setting for one complete cycle, for vertical movement $4 \mathrm{~mm}$ with a speed of $40 \mathrm{~mm} / \mathrm{s}$ and for horizontal movement $1.5 \mathrm{~mm}$ with a speed of $20 \mathrm{~mm} / \mathrm{sec}$ [Figure 1]. Load was maintained at approximately at $60 \pm 5 \mathrm{~N}$ and controlled using dead-weight. ${ }^{[14,16]}$ The applied loads during testing were controlled from force-cell readings in Newton $(\mathrm{N})$. The contact area was not uniform in the entire specimen as shown in Figure 3 from the marking on the indenter which shows the variability of contact area which might lead to variation in the load. To demonstrate 5 years in oral service, the samples were undergo $1,250,000$ complete cycles; one cycle includes axial and lateral movements to simulate 5 years of in oral service. ${ }^{[9]}$ Monoloading tests were performed under the same conditions as the cyclic testing. The specimens were loaded axially along the vertical axis of the specimen and monotonically at a crosshead speed of $0.1 \mathrm{~mm} / \mathrm{min}$ (loading rate $\sim 10 \mathrm{Nmin}^{-1}$ ). ${ }^{[17,18]}$ Record of critical loads to initiate damage was established at intervals of 250,000 cycles during cyclic loading. During mono loading, samples continually monitored during testing and photographed at intervals of 100$200 \mathrm{~N}$.

\section{RESULTS}

Figure 4 shows the means and standard deviations of critical loads when radial cracks observed at the

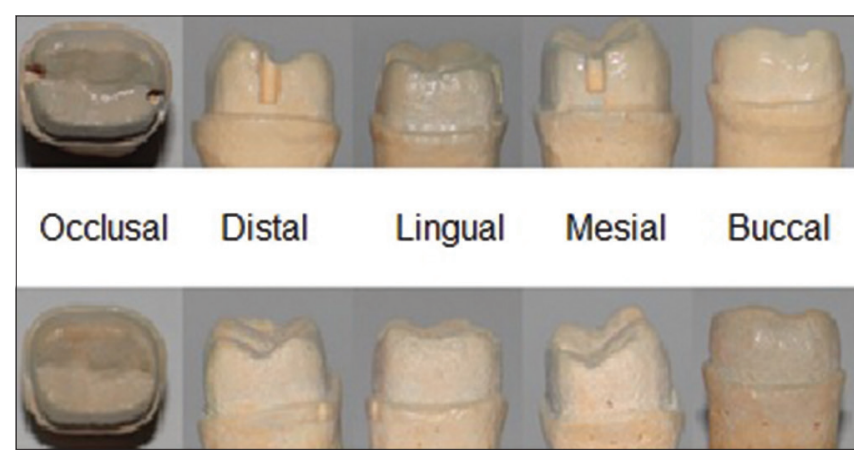

Figure 2: Different views of the abutments used in this study after duplication and the addition of grooves in one of the abutments to insure standardization of the abutment and to minimize the variables to only the grooves addition

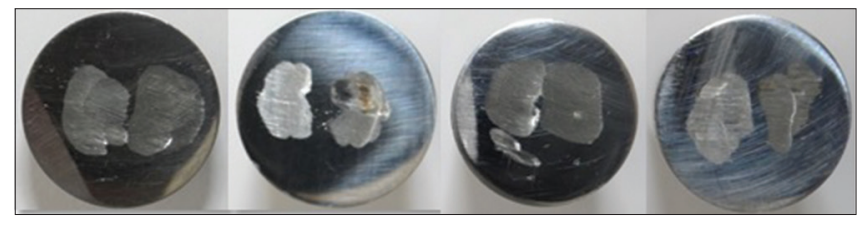

Figure 3: The wear on the stainless steel indenters of four samples after $1,250,000$ cycles in the chewing simulator facing the veneering layer of the crown occlusal surfaces

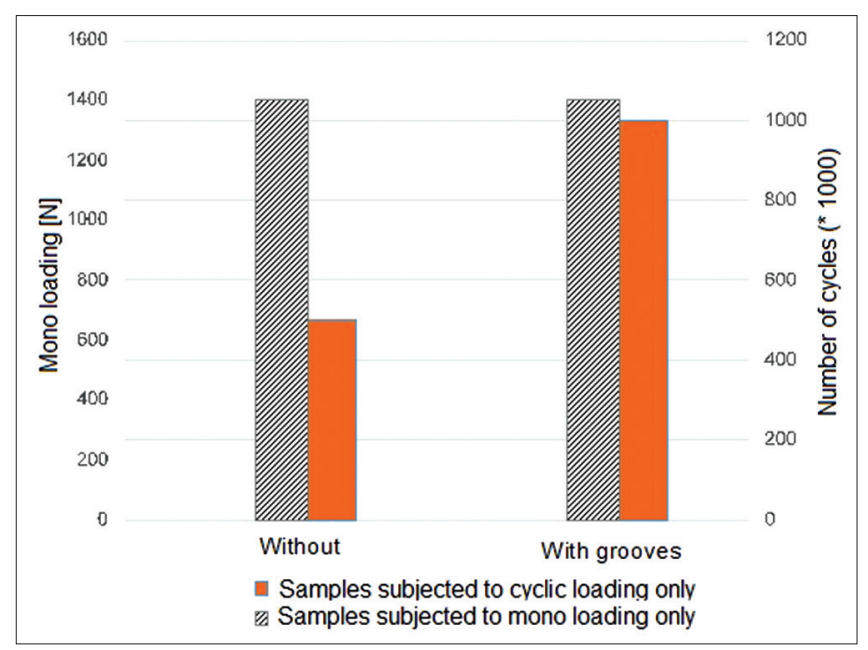

Figure 4: Critical conditions to initiate radial cracks for samples with and without resistance grooves. The error bars approximate the interval at which data taken

end of each interval (250,000 cycles) for both grooved and ungrooved samples. The error bars give an approximate value of the intervals between loading and unloading when the cracks were not monitored during cyclic loading for both grooved and ungrooved samples. The two modes of loading are presented in Figure 4 for samples subjected to mono loading only; the grooves had no effect on critical loads. These samples were not subjected to cyclic loading which leads to smaller contact areas at the cusps of the crown. The cusps reside next to side surfaces of the crown where damage occurs, no cone cracks were 
observed in any of the specimens tested. The critical loads in this were relatively high $(1400 \mathrm{~N})$ followed by a complete lunar crack failure (chipping of veneering layer) at $2000 \mathrm{~N}$. The critical loads to initiate radial cracks in the case of cyclic loading for samples with grooves were twice the amount of cyclic loading for zirconia core without grooves [Figure 4]. In this case, the cracks propagated upward but remain within the vicinity of the crown extremities.

Representative photographs of failure morphology for samples underwent monoloading are presented in Figure 5. The photographs showed that the damage in the samples from a mono loading at higher critical loads resulted in a larger damage area seen as fully developed cracks leading to dislodgment of veneering in the form of semi-lunar cracks as loading increased to $2000 \mathrm{~N}$.

Figure 6 shows comparison between samples with and without resistance grooves for both cyclic and monoloading. Samples with resistance grooves showed extensive damage in comparison with samples without resistance grooves at the buccal surfaces. More interesting, the extent of damage of mono-loaded samples was more deleterious in all samples examined in this study.

\section{DISCUSSION}

Due to the use of the flat indenter, the contact areas in all samples had a border area of contact in comparison with a traditional spherical indenter used by several researchers. ${ }^{[19,20]}$ This wider contact area kept the occlusal surface under compression stresses during testing shifting the tensile stress regions to the side surfaces of the crown (distal, lingual, mesial, and buccal surfaces). As a result of this stress distribution, no cone cracks were observed on the top surface of all specimens tested, which was consistent with Whitton et al. ${ }^{[21]}$

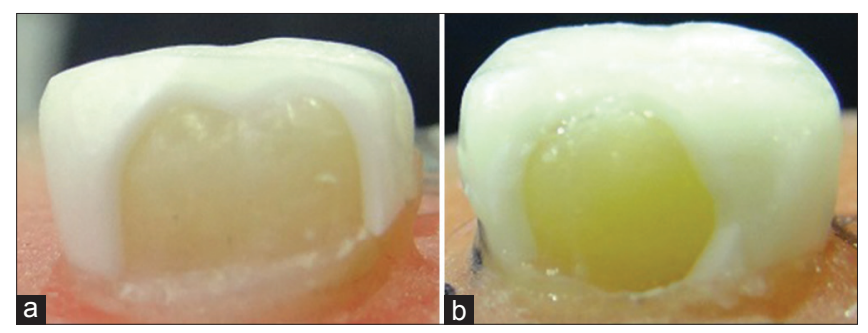

Figure 5: (a) Failure of samples indented mono loading with flat steel indenter load $2000 \mathrm{~N}$, showing damage in buccal surfaces sample without resistance grooves, (b) sample with resistance grooves
In samples subjected to 1,250,000 cycles (cyclic loading only), the addition of grooves showed a remarkable difference in critical loads. There was a doubling increase in the number of cycles for samples with grooves, which could be attributed to the fact that the young modulus of the zirconia core was three times higher than the veneering porcelain. It is well documented that the tensile stress responsible for radial cracks initiation at the cervical surface increases with stiffer core material. ${ }^{[22-24]}$ The addition of grooves in the distal and mesial surfaces of the crown gave these surfaces extra core thickness resulted in an increase in the tensile stress at the cervical surfaces for samples without grooves. In addition, the location of grooves shifted the tensile stress concentration to the buccal surface where most of the observed cracks first appeared. The question that remains unanswered is that the samples have resistance grooves showed extensive damage at buccal surface. This can be attributed to the fact that the energy produced during loading shifted to the surface with thinner zirconia thickness.

The resistance effect of friction force on the horizontal sliding force was not considered significant since all tested specimens were completely immersed in water during testing. The readings of vertical forces during sliding represented the friction force, and the height of the curve for force in Z-direction was increased slightly as number of cycles increased, this could be attributed to the increase in contact area, and hence, the increase of friction force as number of cycles increased.

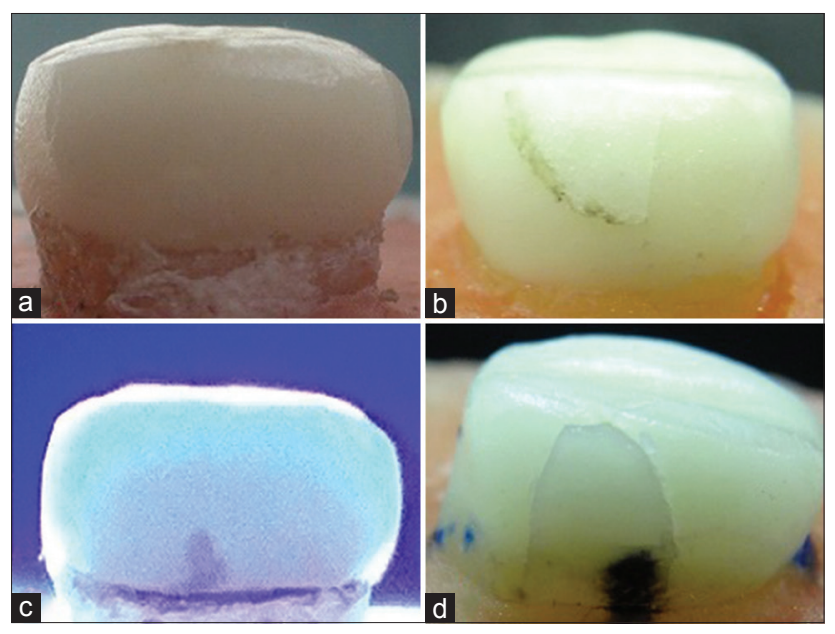

Figure 6: (a) Contact fracture at buccal surface in all ceramic crowns, sample without resistance, 500,000 cycles cyclic loading, (b) sample without resistance grooves, $1400 \mathrm{~N}$ mono loading, (c) sample with resistance grooves, 1,000,000 cycles cyclic loading, (d) sample with resistance grooves, $1400 \mathrm{~N}$ monoloading 


\section{CONCLUSIONS}

The results showed that the location of retention grooves halted the failure in the surfaces where it was located in all loading mechanisms used in this study. The grooves had no effect on the critical loads in the case of a mono loading; in contrast, the samples with grooves doubled the critical number of cycles to initiate radial cracks. As number of cycles increase, the contact area increases, which shifted the tensile, stress region to the side surfaces of the crowns and resulted in fracture at the side surfaces.

\section{Acknowledgments}

The authors gratefully acknowledge Prof. Susan AlKhateeb (Jordan University of science and Technology, Jordan) for many useful discussions and the Scientific Research Support Fund, Jordan.

\section{Financial support and sponsorship}

This work financially supported by a grant from the Scientific Research Support Fund, Jordan (Grant number EIT/2/01/2010).

\section{Conflicts of interest}

There are no conflicts of interest.

\section{REFERENCES}

1. Sakaguchi RL, Powers JM. Craig's Restorative Dental Materials. $13^{\text {th }}$ ed. Elsevier/Mosby, Philadelphia, PA, USA; 2012.

2. Lawn BR, Bhowmick S, Bush M, Qasim T, Recow D, Zhang Y. Failure modes in ceramic-based layer structures: A basis for materials design of dental crowns. J Am Ceram Soc 2007;90:1671-83.

3. Linhares LA, Pottmaier LF, Lopes GC. Fracture resistance of veneers in premolars. Eur J Dent 2018;12:191-8.

4. Zhang Y, Chai H, Lee JJ, Lawn BR. Chipping resistance of graded zirconia ceramics for dental crowns. J Dent Res 2012;91:311-5.

5. Kim B, Zhang Y, Pines M, Thompson VP. Fracture of porcelain-veneered structures in fatigue. J Dent Res 2007;86:142-6.

6. Beuer F, Aggstaller H, Edelhoff D, Gernet W, Sorensen J. Marginal and internal fits of fixed dental prostheses zirconia retainers. Dent Mater 2009;25:94-102.

7. Beuer F, Stimmelmayr M, Gernet W, Edelhoff D, Güh JF, Naumann M, et al. Prospective study of zirconia-based restorations: 3-year clinical results. Quintessence Int 2010;41:631-7.

8. Mukmin I, Qasim T, Hu XZ. Contact damage of curved zirconia/epoxy bi-layers. Strength Fract Complex 2007;4:213-23.

9. Donny PV. Zirconia abutments: Modern day implantology. Int J Oral Implantol Clin Res 2012;3:133-7.

10. Potts RG, Shillingburg HT Jr., Duncanson MG Jr. Retention and resistance of preparations for cast restorations 1980. J Prosthet Dent 2004;92:207-12.

11. Parker MH, Gunderson RB, Gardner FM, Calverley MJ. Quantitative determination of taper adequate to provide resistance form: Concept of limiting taper. J Prosthet Dent 1988;59:281-8.

12. Parker MH. Resistance form in tooth preparation. Dent Clin North Am 2004;48:v-vi, 387-96.

13. Ozcan N, Sahin E. In vitro evaluation of the fracture strength of all-ceramic core materials on zirconium posts. Eur J Dent 2013;7:455-60.

14. Kern M, Strub JR, Lü XY. Wear of composite resin veneering materials in a dual-axis chewing simulator. J Oral Rehabil 1999;26:372-8.

15. Nilavarasan N, Hemalatha R, Vijayakumar R, Hariharan VS. Comparison of compressive strength among three different intracanal post materials in primary anterior teeth: An in vitro study. Eur J Dent 2016;10:464-8.

16. Stawarczyk B, Ozcan M, Roos M, Trottmann A, Hämmerle CH Fracture load and failure analysis of zirconia single crowns veneered with pressed and layered ceramics after chewing simulation. Dent Mater J 2011;30:554-62

17. Qasim T, Bush M, Hu XZ. The influence of complex surface geometry on contact damage in curved brittle coatings. Int J Mech Sci 2006;48:244-8

18. Qasim T, Ford C, Bush M, Hu XZ, Bongué-Boma M. Effect of coating thickness on crack initiation and propagation in non-planar bi-layers. Mater Sci Eng 2006;419:189-95.

19. Qasim T, Bush MB, Hu X, Lawn BR. Contact damage in brittle coating layers: Influence of surface curvature. J Biomed Mater Res B Appl Biomater 2005;73:179-85.

20. Rudas M, Qasim T, Bush M, Lawn B. Failure of curved brittle layer systems from radial cracking in concentrated surface loading. J Mater Res 2005;20:2812-9.

21. Whitton A, Qasim T, Ford C, Hu XZ, Bush M. The role of skirt geometry of dental crowns on the mechanics of failure: Experimental and numerical study. Med Eng Phys 2008;30:661-8.

22. Barani A, Chai H, Lawn BR, Bush MB. Mechanics analysis of molar tooth splitting. Acta Biomater 2015;15:237-43.

23. Lu PC, Wilson P. Effect of auxiliary grooves on molar crown preparations lacking resistance form: A laboratory study. J Prosthodont 2008;17:85-91.

24. De Jager N, de Kler M, van der Zel JM. The influence of different core material on the FEA-determined stress distribution in dental crowns. Dent Mater 2006;22:234-42. 